\title{
Corrigendum
}

\section{BCL-2 family member BOK is widely expressed but its loss has only minimal impact in mice}

\author{
F Ke, A Voss, JB Kerr, LA O’Reilly, L Tai, N Echeverry, P Bouillet, A Strasser and T Kaufmann
}

Cell Death and Differentiation (2013) 20, 183; doi:10.1038/cdd.2012.143

Correction to: Cell Death and Differentiation (2012) 19, 915-925; doi: 10.1038/cdd.2011.210; published online 27 January 2012

Since the publication of this issue, the authors have noticed that the $y$-axis numbers for the PN11 panel in Figure $3 b$ had to be amended to be comparable to each of the other panels in this Figure. The original numbers for PN11 (1, 2 and 3) were related to per $10000 \mu \mathrm{m}^{2}$ ovary section, but now are corrected to be per $\mathrm{mm}^{2}(100,200,300)$. The adjusted values do not alter the corresponding results and interpretations as presented, nor the conclusions reached in the study, namely that loss of Bok does not cause an alteration in the numbers of primordial, primary or secondary follicles in the ovaries of mice aged 11 days, 14 weeks, 7 months or 1 year. The correct figure is shown below.

The authors would like to apologize for any inconvenience this may have caused.

a
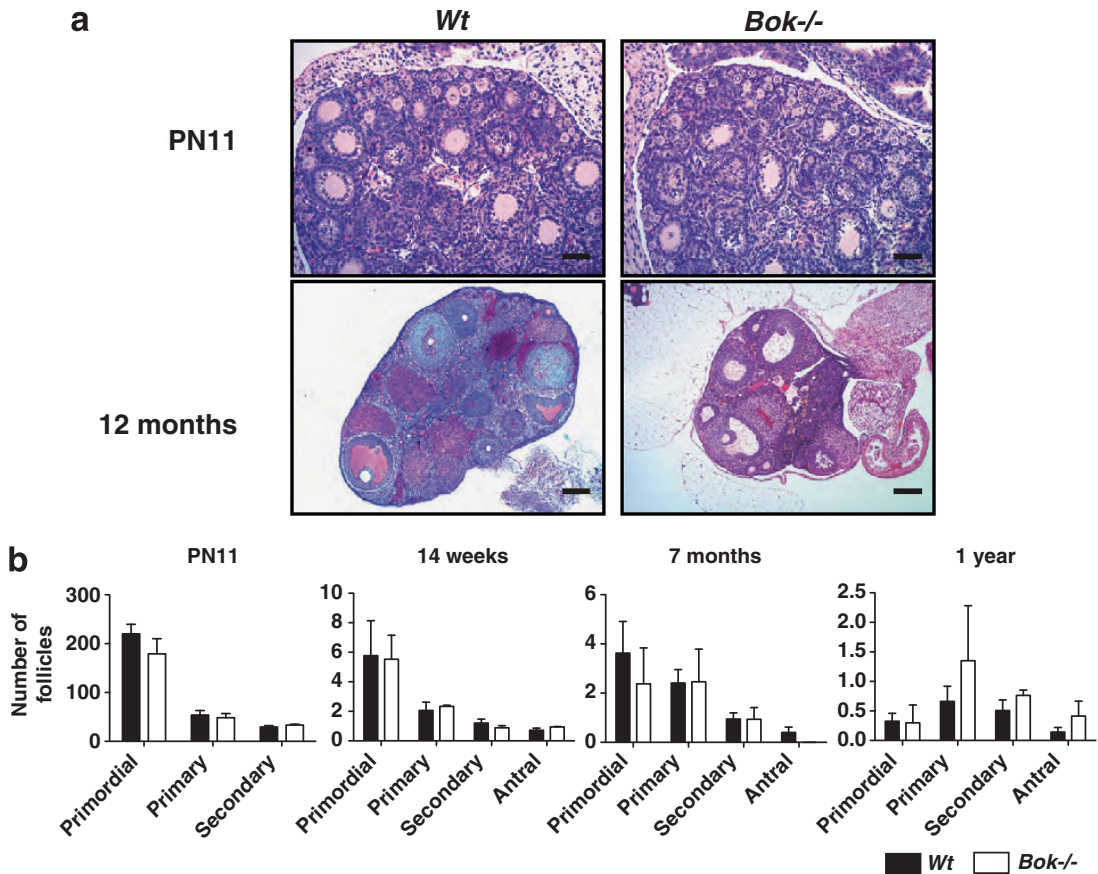

C
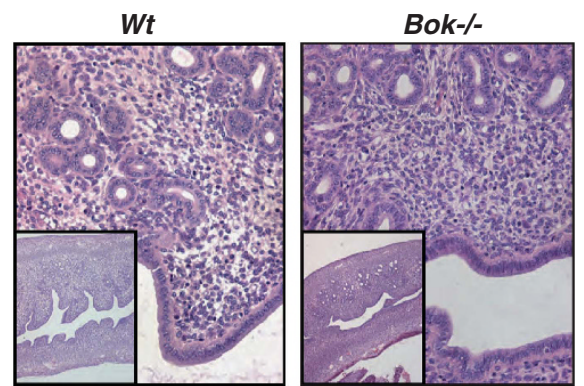

Figure 3 Reproductive organs in female Bok ${ }^{-1-}$ mice are of normal appearance. Histological sections from ovaries and uteri of 14-16-week-old Bok ${ }^{-1-}$ and wt mice were stained with haematoxylin plus eosin and examined by microscopic analysis. (a) Ovaries of wt and Bok ${ }^{-1}$ mice at post-natal day 11 (magnification bar $1 / 450 \mathrm{~mm}$ ) and 12 months of age (magnification bar $1 / 4200 \mathrm{~mm}$ ). Images of 14 week- and 7-month-old ovaries were also examined but are not shown. (b) Graphs depict the mean score for each follicle type in the ovary, which are expressed as numbers per $\mathrm{mm}^{2}$. Data represent the mean \pm S.E.M. of follicle numbers from 3-6 mice of each genotype. (c) Images showing the morphology of the uterus from wt and Bok ${ }^{-1-}$ mice shown at $\times 5$ (inset) and $\times 20$ magnification 